\title{
EDUCAÇÃO A DISTÂNCIA VIA INTERNET EM GRANDES EMPRESAS BRASILEIRAS
}

DISTANCE LEARNING VIA THE INTERNET IN MAJOR BRAZILIAN COMPANIES

\section{RESUMO}

O presente trabalho tem o objetivo de identificar as características das iniciativas de Educação a Distância via Internet em grandes empresas privadas brasileiras. Para isso, foram entrevistados 12 profissionais de Recursos Humanos de grandes empresas envolvidos em programas de EADI. Os resultados da pesquisa consistem numa descrição das características dessas iniciativas, tais como a estrutura dos cursos, seus respectivos públicos-alvo, tecnologias empregadas, métodos para avaliação, entre outros aspectos.

\section{Tatiana Ghedine}

Doutora em Administração pela Escola de Administração, Universidade Federal do Rio Grande do Sul

tghedine@gmail.com

\section{Maurício Gregianin Testa}

Professor do Programa de Pós-Graduação em Administração da Faculdade de Administração, Contabilidade e Economia, Pontifícia Universidade Católica do Rio Grande do Sul

mauricio.testa@pucrs.br

\section{Henrique Mello Rodrigues de Freitas}

Professor do Programa de Pós-Graduação em Administração da Escola de Administração, Universidade Federal do Rio Grande do Sul hf@ea.ufrgs.br

Recebido em 21.02.2006. Aprovado em 25.06.2007

Avaliado pelo sistema double blind review

Editor Científico: Rodrigo Bombonati

\begin{abstract}
The objective of this work is to identify the characteristics of the initiatives in distance learning via the Internet in major private Brazilian companies. To do so, 12 Human Resource professionals from major companies involved with distance learning via the Internet were interviewed. The results of the research comprise a description of the characteristics of the initiatives, such as the structure of the courses, their respective target-audience, the technology used, assessment methods and other aspects.
\end{abstract}

PALAVRAS-CHAVE Educação a distância, ambientes virtuais de aprendizagem, e-learning, desenvolvimento de pessoal, internet. KEYWORDS Distance learning, virtual learning environments, e-learning, personnel development, Internet. 


\section{INTRODUÇÃO}

A Educação a Distância via Internet (EADI) surge como uma das principais soluções para a capacitação de colaboradores nas organizações (SALAS e outros, 2002; ROSENBERG, 2002). O aumento no número de cursos de EADI promovidos pelas organizações é potencializado por diversos fatores: o alto custo da educação tradicional; a rapidez da mudança nos conteúdos desses cursos; as limitações de ordem temporal - ditadas por horários de trabalho e por dificuldades de deslocamento; a importância crescente de uma aprendizagem continuada; as limitações geográficas - impossibilitando o deslocamento de potenciais alunos locados em regiões mais distantes; a evolução das tecnologias interativas de comunicação; entre outros importantes aspectos (ALAVI e LEIDNER, 1994;HÄMÄLÄINEN, WHINSTON e VISHIK, 1996; ROSENBERG, 2002).

Apesar de ser verdade que a Internet vem sendo utilizada na criação de ambientes virtuais de aprendizagem, tanto por organizações empresariais quanto por instituições de ensino, é preciso levar em consideração que os programas de EADI nesses dois tipos de organização apresentam diferenças significativas, uma vez que o ambiente, as demandas e os resultados são distintos (SALAS e outros, 2002). Welle-Strand e Thune (2003) afirmam que o aprendizado nas organizações tem como principais objetivos os de servir às metas e às necessidades corporativas e, normalmente, de aumentar a produtividade, o lucro e a eficiência, o que não ocorre nas instituições educacionais. Assim, essas diferenças devem ser levadas em consideração quando se transporta o resultado de pesquisas desenvolvidas em instituições de ensino para o ambiente empresarial.

A despeito das diferenças que podem ser constatadas entre o ambiente empresarial e o das instituições de ensino, existem poucos estudos que analisam a utilização da EADI nas empresas (SALAS e outros, 2002); a maioria deles é realizada em instituições de ensino. Surge, daí, a seguinte questão: quais seriam então as características dos programas de EADI desenvolvidos pelas empresas no Brasil? Na busca de uma resposta para essa pergunta, o presente trabalho foi desenvolvido com o objetivo de identificar as características das iniciativas de EADI em grandes empresas privadas brasileiras no período de 2002-2003. O foco nas grandes empresas deve-se ao seu pioneirismo na realização de iniciativas de EADI, pois ainda são poucas as empresas de pequeno e médio portes que fazem uso de tecnologias ligadas à Internet no desenvolvimento de seus cursos internos de capacitação de pessoal.
O presente artigo, dividido em quatro seções, apresenta na próxima etapa uma síntese do referencial teórico que orientou a realização da pesquisa. Posteriormente, é descrito o método de pesquisa que permitiu alcançar os resultados. Esses são analisados e discutidos na terceira seção. Na última etapa, desenvolvem-se as considerações finais, apontando as contribuições e os limites do estudo.

\section{A EDUCAÇ̃̃O A DISTÂNCIA VIA INTERNET: DEFINIÇÕES E CARACTERÍSTICAS}

Muitas opções de ambientes e sistemas para gerenciamentos de cursos de EADI estão disponíveis no mercado para os gerentes de treinamento interessados em implementar uma solução de Educação a Distância (EAD) em suas organizações. Embora essas opções possam ser diferenciadas por detalhes particulares, tais como interface do usuário e interatividade, essas soluções têm convergido para uma mesma tecnologia, a Internet. Ao propiciar a criação de ambientes virtuais de aprendizagem caracterizados por uma flexibilidade de tempo, local, conteúdo e forma de instrução sem precedentes, a Internet possibilita que os estudantes estejam potencialmente habilitados para aprender o que precisarem, no momento e no local em que puderem, e também no formato e no ritmo mais apropriados (URDAN e WEGGEN, 2000; PICCOLI, AHMAD e IVES, 2001).

Por outro lado, a Internet trouxe consigo um item fundamental para o processo de ensino e aprendizagem a distância: a interação entre estudantes e instrutores ou professores (CHEONG, 2002). Ao contrário das tradicionais tecnologias de EAD, como os cursos recebidos via Correio e os telecursos, na Internet é possível criar ambientes interativos de aprendizagem, utilizando uma variedade de recursos de comunicação, como chats, videoconferências, fóruns de discussão, e-mails etc.

Salomon e Almog (1998) destacam que essa interação serve para uma variedade de funções cruciais em um processo de aprendizado. Essas funções vão desde a provisão de feedback, que reflete o estímulo e a correção intelectual mútua entre os estudantes, passando pela estruturação conjunta da compreensão, até o compartilhamento social na construção de significados. Esses autores acreditam que pesquisas sobre a aprendizagem colaborativa normalmente tendem a suportar tais concepções, mostrando que, dentro de certas condições, aspectos como os de trabalho em grupo, de colaboração e de ensino recíproco são benéficos para os estudantes. 
Alavi (1994) ressalta que diversos estudos mostraram que a interação entre colegas, em forma de trabalhos em grupo, aumenta a capacidade de pensamento crítico e de resolução de problemas.

Existem, na literatura específica sobre o tema, vários conceitos de EAD, o que indica a falta de um consenso sobre o assunto. Porém, a idéia fundamental da EAD é bastante simples: estudante e professor encontramse separados fisicamente e, na maioria das vezes, também temporalmente (SALAS e outros, 2002; MOORE e KEARSLEY, 1996).

Palloff e Pratt (1999) apresentam cinco elementoschave na definição da EAD: (a) a separação do professor e do estudante durante a maior parte do processo instrucional; (b) a utilização de uma mídia educacional para unir professor e estudante e para "transportar" o conteúdo do curso; (c) a disponibilidade da chamada "comunicação de mão dupla", possibilitando que o estudante se beneficie de um diálogo e da possibilidade de iniciativas de comunicação (sincrônica ou assíncrona); (d) a separação entre professor e aluno, tanto em espaço quanto em tempo; e (e) o aprendizado é controlado pelo estudante, e não pelo professor.

A EADI constitui-se pela convergência, principalmente, de duas áreas: a educacional, que enfatiza os aspectos pedagógicos; e a tecnológica, que trabalha no desenvolvimento de ferramentas para serem utilizadas nos cursos. Os estudos desenvolvidos por áreas diferentes deram origem a vários termos que caracterizam essa nova modalidade de EADI (por exemplo, computer-based learning, web-based learning, virtual classroom e virtual learning environments), sendo que o e-learning é o mais conhecido dentre esses termos, e envolve amplo conjunto de aplicações e processos (URDAN e WEGGEN, 2000; SALAS e outros, 2002).

Quanto aos estudos com ênfase na gestão da tecnologia de informação, existem conceitos próximos à definição de EADI apresentada acima. Alavi e Leidner (2001) definem, por exemplo, "aprendizagem mediada pela tecnologia" como sendo um ambiente no qual a interação dos estudantes com materiais de aprendizado (leituras, tarefas, exercícios etc.), colegas ou instrutores é mediada por avançadas tecnologias de informação. A expressão tecnologias de informação, nesse caso, refere-se às tecnologias de computação, comunicação e gerenciamento de dados. Apesar de não se restringirem somente à Internet como tecnologia, os autores dão amplo destaque aos cursos baseados na Web, deixando implícito que ela efetivamente se constitui como a tecnologia de maior potencial para a EADI.
Outros estudos apontam os benefícios que a EADI pode trazer para as organizações: a diminuição de custos; a apresentação do conteúdo na hora certa e de forma confiável; a necessidade de mínima tecnologia para acesso por parte do estudante; a possibilidade de interações síncrona e assíncrona entre os participantes; a flexibilidade de espaço e de tempo; a possibilidade de escalabilidade - as soluções de e-learning são altamente escaláveis, desde que a infra-estrutura de TI da empresa suporte o aumento no número de alunos -, entre outros (YOUNG, 2001; URDAN e WEGGEN, 2000; ROSENBERG, 2002; WENTLING e outros, 2000; HARUN, 2002; CHEONG, 2002).

Em contraste, Young (2002) aponta alguns fatores como justificativa para a não-adoção da EADI: a tecnologia necessária ainda é muito recente; a TI das organizações pode ser inadequada para esse objetivo; os colaboradores podem ter preferência por cursos tradicionais; e o possível descrédito dos responsáveis pela capacitação na efetividade da EADI.

Em função do crescimento e dos benefícios da EAD, estudiosos da área organizacional têm direcionado a atenção e desenvolvido pesquisas sobre o levantamento de características dos diferentes cursos e das tecnologias neles utilizadas, ainda que existam carências de estudos na área. No Quadro 1, podem ser observados exemplos de aspectos referentes aos cursos de EADI abordados na literatura organizacional.

Existem várias tecnologias de apoio para a interação em cursos via Internet. Entre as que suportam a comunicação síncrona, destacam-se os chats, a teleconferência, a videoconferência, os groupware, os tutoriais computadorizados e os GSS (Group Suport Systems). Para a comunicação assíncrona, podem ser citadas as listas de e-mail, os fóruns de discussão, as aulas pré-gravadas distribuídas via Web e as simulações.

No que tange à avaliação dos cursos, Wentling e outros (2000) dizem que, apesar de o modelo de avaliação de Kirkpatrick (1998) ser comumente aceito pelas organizações, ele é raramente implementado na totalidade e, atualmente, a sua aplicabilidade está sendo amplamente questionada. Assim, as organizações estão repensando como avaliar os seus programas de treinamento, pois métodos antes usados para medir efetividade estão encontrando um ambiente de trabalho diferente daqueles para os quais foram elaborados, e, no ambiente atual, o aprendizado passa a fazer parte integrante das atividades diárias do trabalhador (HACKETT apud WENTLING e outros, 2000).

A implantação efetiva de um programa de e-learning depende de vários fatores. Para Rosenberg (2002), criar 
uma cultura de aprendizado, o alinhamento com uma forte liderança, a comunicação que posiciona o valor do e-learning e a capacidade de mudança que une todos esses fatores são fundamentais. Já Testa e Freitas (2003) procuraram identificar os fatores críticos de sucesso das iniciativas de EADI, e destacam como mais importantes a experiência e a qualificação dos participantes do projeto, as características e o comportamento do estudante, o modelo de aprendizagem, a avaliação da infra-estrutura tecnológica e a formação de parcerias ou alianças estratégicas.

Rosenberg (2002) diz que os problemas culturais são, muitas vezes, a causa do fracasso na continuidade de uma estratégia de EADI, pois o aluno deve passar de uma atitude passiva para outra ativa no processo. Ou seja, ele agora deve se interessar pelo seu aprendizado e buscar o conhecimento. Já em relação ao papel dos gestores nas empresas, a EADI deixa mais evidente a necessidade de gerenciar pessoas e não somente processos e tarefas. Os executivos devem assumir o desenvolvimento de equipes e de pessoas como parte de suas responsabilidades.

\section{MÉTODO DA PESQUISA}

A pesquisa realizada possui natureza exploratório-descritiva (MALHOTRA, 2001). O caráter exploratório do estudo deriva da inexistência de uma base conceitual consolidada sobre EAD na área organizacional (SALAS e outros, 2002). Por outro lado, as principais características das iniciativas de EADI foram levantadas em uma estrutura de coleta de dados típica de um estudo descritivo.

Para a realização da coleta de dados, foi desenvolvido um instrumento quantitativo-qualitativo, formado por questões abertas e fechadas. Essas questões foram desenvolvidas com a intenção de tentar induzir os respondentes a assumir o seu posicionamento, de forma objetiva, a respeito de alguns dos aspectos contemplados

Quadro 1 - Exemplos de aspectos da EADI abordados, conforme apresentados na literatura organizacional

\section{ASPECTOS PESQUISADOS}

Motivos que levam uma organização a apoiar ou não a utilização de EADI como forma de capacitação dos colaboradores.

Assuntos dos cursos; público alvo; duração dos cursos e programas; interação entre os participantes; idiomas utilizados nos cursos; pessoas que cooperam com o curso.

Ferramentas de comunicação e características interativas.

Interações realizadas entre alunos e instrutores.

Idtificação das Taecologias de Informaç̧ão utilizadas.

Como as organizações estão avaliando os cursos de EADI e como estão fazendo para verificar o retorno sobre 0 investimento feito.

Quais os benefícios advindos para as organizações com a utilização da EADI.

Quais as desvantagens e limitações advindas da utilização da EADI.

0 que as organizações estão apontando como maiores dificuldades e pontos de sucesso.

\section{REFERÊNCIAS}

Strazzo e Wentling (2000); Young (2002).

Strazzo e Wentling (2000); Masie (2002); Young (2002).

Urdan e Weggen (2000); Wentling e outros (2000); Rosenberg (2002); Salas e outros (2002); Young (2002).

Testa e Freitas (2003); Salas e outros (2002).

Urdan e Weggen (2000); Strazzo e Wentling (2000); Sallas e outros (2002); Rosenberg (2002); Maia e Meireles (2004).

Wentling e outros (2000); Salas e outros (2002).

Hall (1997); Urdan e Weggen (2000); Wentling e outros (2000); Young (2001); Cheong (2002); Rosenberg (2002); Huran (2002); Rosa e Moreira (2002).

Campbell (1997); Hall (1997); Young (2001); Rosa e Moreira (2002).

Wentling e outros (2000); Rosenberg (2002); Testa e Freitas (2003). 
no presente estudo. Já as questões abertas buscaram um maior aprofundamento em aspectos julgados mais relevantes do tema.

A construção do instrumento de coleta de dados foi baseada no referencial teórico e na realização de duas pré-entrevistas semi-estruturadas, feitas com profissionais responsáveis por iniciativas de EADI em grandes organizações. A primeira entrevista foi realizada com o gerente geral de Recursos Humanos de uma empresa do setor varejista de Porto Alegre (RS), e a segunda, com o gerente de treinamento da área de produção de uma empresa do setor automobilístico de Curitiba (PR). Essas entrevistas, realizadas no ano de 2002, permitiram acrescentar e confirmar variáveis levantadas na literatura, possibilitando corrigir distorções e ajustar o instrumento de pesquisa. O Quadro 2 apresenta as dimensões, os objetivos e as variáveis pesquisadas, sendo que cada dimensão é acompanhada pelos autores em que elas estão embasadas.

O instrumento inicial de pesquisa foi apresentado a dois especialistas, na busca de uma maior validação de conteúdo (NACHMIAS e NACHMIAS, 1996). O primeiro especialista é um acadêmico, e o segundo, um profissional na área de EADI. As sugestões apresentadas por ambos propiciaram melhorias que foram incorporadas ao instrumento.

As doze empresas participantes da pesquisa (realizada em 2003) se localizam nos Estados de São Paulo (dez), Santa Catarina (uma) e Rio Grande do Sul (uma). Todas elas são de grande porte, ou seja, possuem mais de 500 funcionários na classificação do Serviço Brasileiro de Apoio às Micro e Pequenas Empresas (SEBRAE). Quanto aos setores, classificam-se em: serviços públicos (3 empresas); comércio varejista (2 empresas); eletrônico (2 empresas); mecânica (2 empresas); serviço de transporte (1 empresa); automotivo (1 empresa); e tecnologia e computação (1 empresa). Quanto à origem do capital, quatro das doze empresas participantes da pesquisa são de capital nacional, e outras oito, de capital estrangeiro. Dessas, duas possuem centros de treinamento destinados exclusivamente à capacitação de seus colaboradores.

Os respondentes da pesquisa atuam em três diferentes tipos de cargos, mas todos pertencem à área de Recursos Humanos de suas organizações, sendo: dois gerentes de $\mathrm{RH}$; oito gerentes de treinamento e desenvolvimento; e dois analistas de RH. Cabe destacar que, dos doze respondentes, nove deles estão totalmente envolvidos com os cursos de EADI e três outros se dizem parcialmente envolvidos. Esses ocupam o cargo de gerente de treinamento e desenvolvimento, subordinado a um gerente de RH.
Foram entrevistados pessoalmente sete respondentes das empresas de São Paulo, um de Santa Catarina e outro do Rio Grande do Sul. Nos três casos restantes, o instrumento foi enviado e retornou pelo Correio. Vale salientar que, apesar de o instrumento de pesquisa ser estruturado, durante as entrevistas realizadas pessoalmente, buscou-se explorar o fenômeno de forma aprofundada, dando liberdade aos respondentes para emitir suas opiniões (YIN, 2001). Contudo, se é verdade que as entrevistas presenciais trouxeram maior profundidade nas respostas, comparativamente às realizadas por Correio, também é verdade que a análise das respostas não mostrou a existência de diferença significativa entre a percepção dos respondentes dos dois grupos, ainda que essa diferença só tenha sido avaliada qualitativamente.

Finalmente, ressalva-se que, devido ao número de entrevistados, não se podem generalizar os resultados. Contudo, pode-se identificar uma série de convergências nas respostas, o que permitiria levantar hipóteses para um estudo quantitativo futuro.

\section{ANÁLISE DOS RESULTADOS}

Nesta seção, são apresentados os principais resultados obtidos a partir da pesquisa de campo. Primeiramente, são descritas, a seguir, as características básicas das iniciativas de EADI adotadas pelas empresas. Posteriormente, são apresentadas informações sobre os cursos de EADI e são abordados os tópicos relacionados com as tecnologias utilizadas nos cursos. Por fim, a exposição focaliza a temática da avaliação dos cursos.

\section{Características básicas das iniciativas de EADI adotadas pelas grandes empresas brasileiras}

Se, por um lado, uma das vantagens dos cursos de EADI é a flexibilidade para desenvolver atividades de aprendizagem em qualquer horário e local (PICCOLI, AHMAD e IVES, 2001), por outro lado, as empresas brasileiras parecem ainda não explorar muito essa vantagem. Ainda que todas as doze empresas que participaram da pesquisa provejam acesso aos cursos de EADI no local de trabalho, somente cinco delas permitem o acesso completo ao curso fora da empresa, enquanto uma permite o acesso externo a apenas algumas partes de seus cursos e seis não permitem acesso externo ao curso.

Os entrevistados afirmam, de forma geral, que os colaboradores recebem orientação para executar seus cursos em horário de trabalho, o que fica claro nas palavras de um dos entrevistados: "a gente orienta as pessoas a 
tirarem seu telefone do gancho e a não utilizar o e-mail durante o curso, para não terem interferência". Quatro empresas destacaram que a administração do tempo dos colaboradores para fazer os cursos tem sido um problema. Para tentar contornar isso, estão oferecendo cursos de EADI sobre gerenciamento do tempo. Além disso, as

Quadro 2 - Dimensões, objetivos e variáveis pesquisadas, com suas respectivas fontes

\begin{tabular}{|c|c|c|c|}
\hline DIMENSÕES & OBJETIVO & VARIÁVEIS & FONTES \\
\hline $\begin{array}{l}\text { Informações } \\
\text { sobre os } \\
\text { cursos de EADI }\end{array}$ & $\begin{array}{l}\text { Obter informações } \\
\text { mais específicas sobre } \\
\text { os cursos de EADI }\end{array}$ & $\begin{array}{l}\text { - motivo que levou a empresa a apoiar a utilização } \\
\text { da EADI; } \\
\text { - acesso remoto ao curso; } \\
\text { - horário para a realização dos cursos; } \\
\text { - pagamento dos cursos; } \\
\text { - público alvo; } \\
\text { - alcance dos treinamentos; } \\
\text { - certificações e/ou créditos; } \\
\text { - resultado do treinamento; } \\
\text { - temas dos cursos; } \\
\text { - quantidade de cursos a serem promovidos; } \\
\text { - duração média dos cursos; } \\
\text { - média de participantes por curso; } \\
\text { - interações; } \\
\text { - idioma; } \\
\text { - quem coopera nos cursos. }\end{array}$ & $\begin{array}{l}\text { Hall (1997); Alperstedt (2000); } \\
\text { Strazzo e Wentling (2000); } \\
\text { Wentling e outros (2000); Urdan } \\
\text { e Weggen (2000); Harun (2002); } \\
\text { Rosa E Moreira (2002); Rosenberg } \\
\text { (2002); Masie (2002); Young } \\
\text { (2002). }\end{array}$ \\
\hline $\begin{array}{l}\text { Tls utilizadas } \\
\text { nos cursos de } \\
\text { EADI }\end{array}$ & $\begin{array}{l}\text { Obter informações so- } \\
\text { bre alguns itens refe- } \\
\text { rentes às TIs utilizadas } \\
\text { pelas organizações } \\
\text { para a EADI }\end{array}$ & $\begin{array}{l}\text { - acesso à rede; } \\
\text { - comunicação síncrona e assíncrona; } \\
\text { - desenvolve internamente softwares; } \\
\text { - softwares utilizados; } \\
\text { - desenvolvimento de conteúdo; } \\
\text { - forma de apresentação do conteúdo. }\end{array}$ & $\begin{array}{l}\text { Urdan e Weggen (2000); Wentling e } \\
\text { outros. (2000); Strazzo e Wentling } \\
\text { (2000); Rosenberg (2002); Salas } \\
\text { e outros (2002); Young (2002). }\end{array}$ \\
\hline $\begin{array}{l}\text { Avaliação dos } \\
\text { programas de } \\
\text { EADI }\end{array}$ & $\begin{array}{l}\text { Identificar como as or- } \\
\text { ganizações estão ge- } \\
\text { rindo a avaliação seus } \\
\text { cursos de EADI }\end{array}$ & $\begin{array}{l}\text { - avaliação do aprendizado; } \\
\text { - investimento realizado; } \\
\text { - tempo entre a concepção da idéia e a sua } \\
\quad \text { implantação; } \\
\text { - como se calcula o ROI (Return Over Investment); } \\
\text { - vantagens; } \\
\text { - desvantagens; } \\
\text { - dificuldades; } \\
\text { - condição fundamental para que a EADI funcione. }\end{array}$ & $\begin{array}{l}\text { Campbell (1997); Hall (1997); } \\
\text { Meister (1999); Phillips apud } \\
\text { Wentling e outros (2000); Urdan e } \\
\text { Weggen (2000); Wentling e outros } \\
\text { (2000); Young (2001); Cheong } \\
\text { (2002); Rosenberg (2002); Huran } \\
\text { (2002); Rosa e Moreira (2002). }\end{array}$ \\
\hline $\begin{array}{l}\text { Dados } \\
\text { organizacionais } \\
\text { e pessoais do } \\
\text { entrevistado. }\end{array}$ & $\begin{array}{l}\text { Levantar os dados } \\
\text { pessoais e organiza- } \\
\text { cionais necessários } \\
\text { para a pesquisa. }\end{array}$ & \multicolumn{2}{|c|}{$\begin{array}{l}\text { - porte da empresa; } \\
\text { - origem do capital; } \\
\text { - atividade principal; } \\
\text { - cargo do respondente; } \\
\text { - envolvimento do respondente com os programas de EADI; } \\
\text { - sexo; } \\
\text { - idade; } \\
\text { - tempo de serviço na empresa; } \\
\text { - cargo do respondente. }\end{array}$} \\
\hline
\end{tabular}


empresas permitem que os colaboradores permaneçam em suas dependências fora do seu horário para poder completar os cursos.

Nota-se, ainda, uma preocupação, por parte dos organizadores desses cursos, com as condições do local de acesso. Concretamente, isso se reflete na estruturação, na maioria dos casos, de uma sala equipada com microcomputadores e acesso à Intranet, caso o ambiente de trabalho seja muito turbulento ou não possua computadores à disposição dos colaboradores. Em uma das empresas, foi criada uma sala chamada informalmente de "fuga do chefe", uma opção para os colaboradores que não conseguem tempo para estudar no seu posto de trabalho. Esse aspecto aproxima-se da idéia de Campbell (1997) ao mostrar que o aprendizado na própria mesa de trabalho entra em concorrência com as tarefas diárias, podendo gerar conflitos e contribuindo para a intensificação do trabalho.

O público-alvo dos cursos de EADI é composto basicamente pelos próprios colaboradores das empresas, apesar de algumas organizações também oferecerem cursos a empresas parceiras ou com as quais mantenham um relacionamento comercial, conforme mostra a Tabela 1 .

Tabela 1 - Público para o qual os cursos de EADI são dirigidos

\begin{tabular}{|l|c|c|c|c|}
\hline & NUNCA & ALGUMAS VEZES & SEMPRE & TOTAL \\
\hline Clientes Internos (colaboradores da própria empresa) & 0 & 1 & 11 & 12 \\
\hline $\begin{array}{l}\text { Parceiros da empresa (grupo que compõe a cadeia de valor da } \\
\text { organização) }\end{array}$ & 7 & 4 & 1 & 12 \\
\hline Qualquer pessoa da sociedade & 10 & 2 & 0 & 12 \\
\hline
\end{tabular}

Tabela 2 - Nível dos cursos de EADI

\begin{tabular}{|l|c|}
\hline & NÚMERO DE EMPRESAS \\
\hline Somente cursos de nível operacional & 4 \\
\hline Somente cursos de nível tático & 1 \\
\hline Somente cursos de nível estratégico & 2 \\
\hline Cursos de nível tático e estratégico & 3 \\
\hline Cursos de nível operacional e tático & 1 \\
\hline Cursos de nível operacional, tático e estratégico & 1 \\
\hline TOTAL & 12 \\
\hline
\end{tabular}

Raramente tais cursos são abertos para a participação de pessoas externas.

As empresas têm utilizado a EADI para promover cursos de diversas naturezas, como se verifica na Tabela 2, destinados não apenas às áreas operacionais, mas também a níveis estratégicos das organizações. Entretanto, a diversidade, em cada empresa, é limitada: pode ser observado que a maioria delas - sete empresas - direciona seus cursos de EADI apenas para um nível hierárquico específico, enquanto somente uma das empresas pesquisadas está utilizando os cursos de EADI em todos os níveis - operacional, tático e estratégico.

Das empresas analisadas, apenas uma possui cursos de EADI reconhecidos por IES. Na realidade, esses cursos são fornecidos pelas próprias IES, que são responsáveis pelas avaliações e pelo seu andamento. Essa é uma tendência que se repete também quando empresas externas são responsáveis pelo desenvolvimento dos cursos e acabam fornecendo certificados próprios. Cabe destacar que duas das empresas que não fornecem qualquer tipo de certificado ao final dos cursos de EADI registram os resultados nos currículos on line dos colaboradores, uma vez que esses cursos fazem parte do plano de de-

(1)

(n)

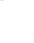


senvolvimento de habilidades e conhecimentos de cada colaborador. Os certificados são emitidos pela própria empresa em cinco casos e quatro delas não fornecem certificados.

Um dos resultados desta pesquisa indica a idéia de que a preocupação das empresas está mais direcionada ao resultado e ao desempenho do trabalho dos profissionais após a realização de um curso - observado em sete empresas do que à qualidade dos profissionais - em cinco empresas. O importante não é somente o currículo do colaborador, mas também a sua competência para conseguir aplicar no trabalho os conhecimentos e as habilidades adquiridos. Cabe destacar que, em quatro empresas, foi afirmado que os gestores de RH não avaliam o resultado dos cursos na busca de uma melhoria na qualidade dos profissionais; e em duas outras, que esses gestores não avaliam os cursos pela melhora do desempenho do trabalho dos profissionais. Os gestores de RH das restantes seis empresas utilizam um procedimento que resulta de uma combinação entre as duas formas de avaliação.

É curioso constatar que, nos anos mais recentes, apesar de os meios acadêmicos parecerem ter dado bastante destaque ao sistema de desenvolvimento de pessoas pautado pela gestão por competências, a maioria das empresas pesquisadas ainda não se apropriou desses conceitos de forma a integrar os cursos de EADI a um plano mais amplo de gestão empresarial. Também pode ser recordado que, segundo alguns autores, competência implica conhecimento (compreensão de conceitos e técnicas), habilidades (aptidão e capacidade de realizar) e atitude (postura, modo de agir), isto é, saberes - fazer, realizar e ser - que, combinados, levariam ao melhor desempenho organizacional (ÉBOLI, 2001; RUAS, 2005).

De fato, os gestores de apenas quatro das doze empresas analisadas afirmaram direcionar seus cursos de acordo com as competências necessárias a serem adquiridas ou desenvolvidas pelos colaboradores. Isso fica claro no discurso de um dos entrevistados: "Nós temos sete ou oito competências que foram apontadas como primordiais para um colaborador fazer parte da empresa. Quando a gente foi adquirir os cursos, buscamos os que tinham ligações com essas competências." Essa situação destacada, entretanto, aparenta não ser a realidade na maioria das empresas, uma vez que as definições dos cursos parecem não estar adequadamente apoiadas em reflexões de caráter mais estratégico.

\section{Informações sobre os cursos de EADI nas empresas}

As empresas estudadas começaram, na sua maioria, a utilizar a EADI para a capacitação de seus colaborado- res em 2001, tendo como exceções uma que iniciou suas atividades em 1997, e outra, em 2003. O respondente deste último caso fez a seguinte observação: "Adotamos uma linha de implantação gradual. Depois de oito meses de experiência é que começamos a abrir para os colaboradores como um todo. Abrimos primeiro somente para os gerentes, depois para outros grupos e agora estamos abrindo para um grupo irrestrito."

Por outro lado, também foi verificado que a data de início da utilização da EADI parece não influir no número de cursos já disponibilizados. Por exemplo, a empresa que começou a utilizar a EADI em 1997 já ofereceu mais de mil cursos, que é quase a mesma quantidade que a de uma das empresas que iniciou a EADI em 2003. Um dos entrevistados fez a seguinte observação: "O importante não é a quantidade de cursos oferecidos, e sim a qualidade desses. Eles devem ser interessantes, atraentes, de fácil manipulação e, principalmente, devem ter um objetivo relacionado com o desenvolvimento do colaborador. Só assim os colaboradores os utilizarão."

Revisando os dados referentes ao ano de 2003, pode ser constatado que o número de novos cursos de EADI oferecidos foi bem variado. Duas dentre as empresas pesquisadas ofereceram mais de 100 novos cursos, cabendo destacar que tais empresas não desenvolveram todos esses cursos, uma vez que são compartilhados entre as filiais espalhadas pelo mundo. Mas a maioria não desenvolveu mais de vinte cursos, sendo que uma empresa criou um único curso. Essa variedade na quantidade dos cursos reflete também a variedade de tipos de cursos: cursos operacionais de curta duração (por exemplo, de duas horas) e de duração mais longa, realizados ao longo de vários meses.

A abrangência dos cursos dentro das organizações pesquisadas é razoável, indicando que os programas de EADI têm uma posição importante no desenvolvimento de capacitações no quadro de pessoal. Em duas das empresas estudadas, todos os colaboradores já participaram de algum curso a distância via Internet. Quase a totalidade dos colaboradores das empresas pesquisadas que possuem acesso aos cursos de EADI já cursou pelo menos uma vez algum curso. Além disso, em apenas três empresas das doze pesquisadas os cursos de EADI não estão disponíveis para todos os colaboradores.

A taxa de abandono dos cursos feitos via Internet tem sido tanto uma preocupação para os pesquisadores quanto para os profissionais de RH envolvidos com a EADI. Três empresas afirmaram que, nos cursos obrigatórios, o índice de evasão é nulo, mas esse índice não serve como referência em relação à efetividade dos cursos. Nos cur- 
sos livres que não são obrigatórios, o percentual de colaboradores que não concluiu os cursos varia bastante, sendo que a taxa média identificada foi de $10 \%$. Entre as razões normalmente atribuídas para esse nível de desistência está a dificuldade dos estudantes em relação à autodisciplina e à auto-regulação da aprendizagem por causa da flexibilidade de tempo, local e recursos dos ambientes virtuais de aprendizagem. Uma segunda razão pode estar na falta de contato social dos cursos on line, que atua como fator motivador importante nos cursos presenciais (SALOMON e ALMOG, 1998; SALAS e outros, 2002).

Uma empresa apresentou uma razão diferente para a taxa de abandono verificada em seus cursos: "Esse valor de $10 \%$ significa que o colaborador foi transferido, demitido ou está fazendo por módulos. É algo difícil de ser controlado. Eu acredito que, por desistência, a taxa não seja superior a $1 \%$, uma vez que a rotatividade da mão-deobra no nosso setor é muito alta." Outra empresa ainda afirma que a utilização de tecnologias da informação inadequadas, no início da utilização da EADI, gerou grande desistência, o que não ocorre atualmente.

Os cursos de EADI podem ser realizados em turmas (com interações tanto síncrona quanto assíncrona), que é o formato utilizado em três das empresas, ou de forma individual (que é o tipo característico de cursos predominantemente assíncronos), modelo utilizado em onze empresas. Cabe salientar que duas das três empresas que possuem cursos no formato de turmas também possuem cursos individuais. Em uma dessas, a média de participantes por turma é de oito alunos, e na outra, de vinte. A empresa que realiza cursos de EADI somente em turmas tem, como número mínimo, dez participantes, e como máximo, vinte. Essa empresa alega que esse é um número ideal para se ter maior controle sobre as atividades dos estudantes. Se houver mais de vinte colaboradores interessados em fazer o curso, abre-se uma nova turma. Finalmente, nove empresas realizam somente treinamentos individuais. A diferença essencial entre os dois formatos está no projeto pedagógico dos cursos. Enquanto cursos individuais focam essencialmente a auto-instrução, dentro de uma abordagem comportamentalista da aprendizagem, os cursos baseados em turmas valorizam a interação entre os participantes e desses com os instrutores como elemento importante na construção do conhecimento, de acordo com um modelo mais colaborativo (LEIDENER e JARVENPPA, 1995).

Por outro lado, também foi constatado que somente uma das empresas possui constantemente interação entre os participantes dos cursos e os professores/tutores, pois os cursos são desenvolvidos em turmas, facilitando a interação. Assim, a maioria dos cursos de EADI promovidos pelas empresas pesquisadas foca a auto-instrução ou o autodesenvolvimento. Os entrevistados disseram que existem, à disposição dos participantes de seus cursos, recursos como chats e listas de discussões, porém não são muito utilizados. Um dos motivos é o despreparo de algumas empresas na utilização de tais ferramentas: "No início, começamos com um fórum de discussão. Mas imagina a confusão, com quatro mil pessoas interagindo e fazendo os cursos de forma individual. [...] Não estávamos preparados para isto. Então, paramos de utilizar o fórum, e estamos repensando em como utilizá-lo de uma forma mais adequada."

Quanto aos temas dos cursos, onze empresas oferecem cursos que objetivam melhorar as soft skills, e seis delas também oferecem treinamentos de aplicação para computadores pessoais. O público-alvo dos treinamentos de EADI é composto, na sua maioria: pelo pessoal técnico, para onze empresas; por integrantes da área operacional, para dez empresas; por gerentes, para dez empresas; por diretores, para nove empresas; e por vendedores, para sete empresas. Essa constatação pode ser corroborada pelo fato de que a maioria dos cursos de EADI é dirigida para os níveis operacional e tático.

Quanto à equipe que participa dos cursos de EADI, observa-se ainda que sete empresas preocupam-se em fornecer suporte técnico para a utilização da tecnologia nelas adotada. Outras seis valem-se de tutores que são, em sua maioria, colaboradores que recebem treinamento para atuar nessa função. Alguns desses possuem até mesmo cursos de mestrado e doutorado, porém os que não possuem tais títulos são colaboradores que conhecem muito bem o conteúdo em estudo. Outras três utilizam professores e duas não utilizam nenhuma forma de cooperação.

Os cursos externos utilizados pelas empresas oferecem o apoio de professores aos colaboradores. Cabe salientar que apenas duas das empresas pesquisadas não disponibilizam qualquer tipo de apoio ao aluno. A equipe de suporte técnico está disponível em sete empresas, mas durante os fins de semana somente em três delas; em uma destas, o suporte técnico fora do horário de expediente é fornecido por uma das sedes da empresa, localizada na Europa.

Todas as empresas entrevistadas possuem cursos em português, e oito delas possuem esses cursos em pelo menos três idiomas. Dentre as empresas de capital estrangeiro, duas iniciaram os cursos de EADI no Brasil, e uma delas já expandiu os seus cursos para outras filiais, que atuam em países de língua inglesa e hispânica. O in- 
glês é o idioma mais utilizado nas empresas estrangeiras analisadas. Como disse um dos entrevistados, "a maioria dos cursos que temos é em inglês, pois é a língua da companhia [...] faz parte do perfil dos colaboradores". Entretanto, vale destacar que as próprias empresas assumem que existe dificuldade quanto à utilização do inglês nos cursos, pois muitos dos colaboradores não dominam o idioma, dificultando a aprendizagem. Somente uma das empresas de capital estrangeiro não possui cursos em inglês, uma vez que os cursos de EADI surgiram no Brasil, e os mesmos ainda não são utilizados nas demais filias no exterior.

\section{Tecnologias utilizadas nos cursos de EADI}

Todas as empresas pesquisadas oferecem acesso aos cursos via Intranets, enquanto, em cinco delas, também é oferecido o acesso por Extranets, e em quatro outras, pela Internet. $\mathrm{O}$ acesso por Extranet confere com o exposto anteriormente, quando foi identificado que cinco empresas permitem que seus cursos sejam acessados pelos alunos fora do local de trabalho. Três dessas empresas também oferecem acesso pela Internet, sobretudo quando os cursos são controlados por uma organização externa e são realizados na forma assíncrona.

Essa característica de fornecer cursos de EADI com comunicação somente assíncrona corrobora o que é exposto abaixo, na Tabela 3. Dessa forma, as empresas estão deixando de utilizar um dos recursos diferenciais dos cursos de EADI: a interação entre os participantes e desses com os tutores.

Quanto ao desenvolvimento e à programação dos cursos, dez empresas adquirem os chamados "cursos de prateleira", já desenvolvidos e disponíveis no mercado. Porém, seis empresas também contratam outras organizações para desenvolver cursos personalizados. Somente cinco empresas, todas de capital estrangeiro e de alguma maneira ligadas à área de tecnologia, pos- suem capacidade para desenvolver seus próprios cursos. Entretanto, isso não as impede de adquirir cursos prontos.

A maioria das doze empresas analisadas utiliza sistemas comerciais prontos, para o apoio na gestão dos cursos, tais como os LMS (Learning Management System), como Lotus Note, Learning Space, Saba, Interwise, entre outros. Apenas duas empresas desenvolvem internamente os seus ambientes virtuais de aprendizagem e os respectivos sistemas de gestão. Essa opção, apesar de eventualmente demandar mais tempo e recursos, permite às empresas desenvolver cursos em um formato mais adequado às suas necessidades. Além disso, é importante ressaltar que ainda existem críticas em relação à efetividade dos sistemas prontos para a EADI, pois, apesar de incorporarem praticamente todas as tecnologias relacionadas à Internet existentes, são acusados, em certos casos, de se basearem em princípios pedagógicos inadequados e ultrapassados (TESTA e FREITAS, 2003).

Pode-se observar, na Tabela 4, que a maioria das empresas desenvolve o conteúdo para seus cursos, porém nada as impede de adquiri-los prontos, ou de contratar uma empresa para prestar-lhes este serviço. Um dos entrevistados informou que, quando o conteúdo dos "cursos de prateleira" não se encaixa na realidade da empresa, ele solicita adaptações.

De acordo com a Tabela 5, textos, figuras e fotografias são as formas de apresentação de conteúdo mais utilizadas nos cursos. O som não é utilizado por três empresas, pois os equipamentos disponibilizados aos colaboradores não são dotados de aparelhagem multimídia. Porém, pretendem adaptá-los. Foi ainda observado que as simulações geralmente estão presentes na parte de exercícios ou de avaliação dos cursos. Essas simulações procuram se aproximar o máximo possível da realidade, para detectar se realmente o aluno compreendeu o conteúdo e se sabe aplicá-lo de forma prática.

Tabela 3 - Tecnologias de comunicação utilizadas nos cursos de EADI

\begin{tabular}{|l|c|}
\hline \multicolumn{1}{|c|}{ TECNOLOGIAS DE COMUNICAÇÃO } & NÚMERO DE EMPRESAS* \\
\hline Fóruns de discussão & 7 \\
\hline Chats & 6 \\
\hline Nenhum meio de comunicação & 5 \\
\hline Lista de e-mails & 3 \\
\hline Videoconferência via Internet & 1 \\
\hline * Resposta múltipla. Total 12 respondentes.
\end{tabular}




\section{Avaliação dos cursos de EADI pelas organizações}

Os cursos de EADI estão sendo avaliados de diversas formas. Sete das empresas pesquisadas estão aplicando provas on line para a avaliação do aprendizado, porém essa não é a única forma de avaliação utilizada em cinco destas. Uma empresa aplica, complementarmente, os quatro níveis de avaliação propostos por Kirkpatrick (1998) - reação dos aprendizes; aprendizado; aplicação no trabalho; e impacto organizacional -, enquanto outra realiza um constante monitoramento de cada aluno durante todo o curso. Outras duas empresas realizam uma avaliação de reação juntamente com a prova on line, ao passo que outra realiza um pré-teste e um pós-teste para verificar o aproveitamento do aluno.

Cabe salientar que três empresas não realizam qualquer tipo de avaliação on line. Baseiam-se somente no feedback informal dado pelos colaboradores e gerentes quanto aos cursos e ao impacto no trabalho, apesar de reconhecerem que devem começar a pensar em um método de avaliação mais formal. Por fim, uma das empresas analisadas somente realiza uma avaliação de reação sobre o curso.
O investimento inicial realizado pelas empresas para disponibilizar cursos de EADI é bem variado. Duas empresas disseram que tiveram o custo reduzido, pois não adquiriram qualquer LMS (ou equivalente), e que contrataram os serviços de uma empresa para conduzir os cursos de EADI. Esses cursos mesclam aulas transmitidas via televisão e Internet. Isso fica claro nas palavras do entrevistado de uma dessas duas empresas: “[...] o valor do investimento não foi maior do que R\$ 100.000,00. O que mais gastamos foi na estrutura para acessar os cursos, televisores, salas com computadores com condições de acessar bem a Internet, as antenas, os decodificadores. Não precisamos gastar dinheiro com a preparação dos cursos, porque eles já vêm prontos".

Duas outras empresas afirmaram que gastaram em torno de $\mathrm{R} \$ 70.000,00$ no investimento inicial, desenvolvendo seu LMS e as páginas na Internet. Por outro lado, uma empresa informou que gastou em torno de $\mathrm{R} \$ 400.000,00$ no desenvolvimento dos cursos, aquisição de computadores e preparação das salas de treinamento. E, finalmente, uma última empresa afirmou não ter idéia

Tabela 4 - Desenvolvimento do conteúdo dos cursos de EADI

\begin{tabular}{|l|c|}
\hline & NÚMERO DE EMPRESAS* \\
\hline Sim. Desenvolve o conteúdo. & 9 \\
\hline Não. Adquire conteúdos prontos. & 7 \\
\hline Não. Contrata-se uma empresa para desenvolvê-lo. & 3 \\
\hline Não. Somente adapta o conteúdo. & 1 \\
\hline Sem resposta. & 1 \\
\hline
\end{tabular}

*Resposta múltipla. Total de 12 respondentes.

\section{Tabela 5 - Formas utilizadas para o conteúdo dos cursos}

\begin{tabular}{|l|c|}
\hline \multicolumn{1}{|c|}{ FORMAS DE APRESENTAÇÃO } & NÚMERO DE EMPRESAS* \\
\hline Textos & 12 \\
\hline Figuras (gráficos, desenhos) & 12 \\
\hline Fotografias & 11 \\
\hline Sons & 9 \\
\hline Imagens em movimento & 8 \\
\hline Jogos & 8 \\
\hline Simulações & 7 \\
\hline resposta múltipla. Total 12 participantes. & 7 \\
\hline
\end{tabular}


do valor do investimento inicial, mas tem certeza de que, durante dois anos de utilização da EADI, gastou mais de um milhão de reais. Esses valores comprovam que os investimentos realizados pelas empresas são significativos e que as organizações apostam efetivamente na EADI como uma estratégia válida para a capacitação de pessoal.

Desde que surgiu a idéia de adoção da EADI para a capacitação dos colaboradores, as empresas levaram, em média, seis meses para começar a utilizar os cursos. Porém, uma delas disse que passou dois anos analisando e pensando a melhor forma de utilizar a EADI para a capacitação dos seus colaboradores. Duas outras empresas disseram que seria difícil estimar quanto tempo foi necessário, desde a concepção da idéia inicial até o início das atividades dos cursos.

Em relação à forma de avaliação do retorno do investimento em Educação a Distância dentro das empresas analisadas, foi constatada a existência de três principais correntes. A primeira delas é essencialmente baseada no custo comparativo pela verificação do retorno ao comparar os gastos do treinamento presencial com o virtual. Uma segunda forma mais ampla baseia-se na verificação do retorno a partir dos resultados do negócio, procurando identificar se houve associação entre o desempenho dos colaboradores e o alcance dos objetivos das diversas áreas funcionais. Finalmente, existe um grupo de empresas que não realiza qualquer tipo de análise de retorno sobre o investimento.

Os entrevistados opinaram sobre as vantagens dos cursos de EADI, de acordo com o que eles próprios vivenciam em suas empresas. As seis principais vantagens levantadas pelos entrevistados, seguidas da quantidade de citações, foram:

- atinge um grande número de pessoas ao mesmo tempo e em diferentes locais (doze);

- facilidade de aumentar o número de alunos por curso (dez);

- redução do custo total com treinamento (nove);

- aprendizado disponível a qualquer hora (nove);

- conteúdo facilmente atualizável, o que aumenta a confiança por parte do estudante (oito);

- aumento do interesse dos colaboradores no processo de capacitação (oito).

Os entrevistados também emitiram suas opiniões quanto às desvantagens dos cursos de EADI. As seis desvantagens mais citadas pelos respondentes, seguidas da quantidade de citações, foram:

- altos custos iniciais dos programas (oito);

- dificuldade de encontrar um método de avaliação confiável (sete);
- falta de socialização entre os participantes (sete);

- exigência de elevado conhecimento na compreensão de textos (seis);

- abandonos causados por falta de bom acompanhamento do processo (seis);

- falta de familiaridade de algumas pessoas com o funcionamento do computador (seis).

Também foram levantadas, pelos entrevistados, algumas das condições consideradas como fundamentais para que a EADI produza resultados:

- necessidade de um líder engajado no processo, que ocupe uma posição hierárquica mais alta;

- adequação cultural e ambiental: deve haver uma mudança na cultura de aprendizado dos colaboradores e de toda a empresa em si. Ou seja, além de o trabalhador ter que mudar a sua forma de aprendizagem - pois agora ele é responsável pelo seu próprio aprendizado -, a empresa tem que oferecer ao seu colaborador, em contrapartida, um ambiente propício ao autodesenvolvimento;

- plano de comunicação eficiente e eficaz sobre a capacitação através da EADI, tendo como objetivo despertar o interesse do colaborador e mostrar-lhe os benefícios que obterá com essa forma de capacitação;

- uma ferramenta eficiente e eficaz: o uso de recursos sonoros como "Oh, oh! Você errou a resposta, tente novamente!", segundo um dos entrevistados, "pode acabar irritando as pessoas". A ferramenta também deve ser rápida: "na hora em que o colaborador clicar, a próxima tela tem que abrir rápido, senão ele desiste", disse outro entrevistado. Outro respondente afirmou que, quanto mais interativos e lúdicos forem os cursos, maior será a satisfação dos alunos, "[...] afinal, é uma linguagem gostosa [...] aprende-se brincando".

As duas condições mais apontadas como fundamentais pelos entrevistados vão ao encontro das duas maiores dificuldades levantadas na pesquisa: mudança de cultura do indivíduo, que passa a ser responsável pelo seu próprio aprendizado, e comprometimento dos líderes da organização. O terceiro fator levantado nas dificuldades - o da "definição clara de uma estratégia de aprendizado" - corrobora a necessidade de se "desenvolver um projeto pedagógico consistente", que foi também uma das condições fundamentais levantadas para a capacitação através da EADI, porém com poucas citações (apenas duas).

A última questão respondida pelos entrevistados se referia ao nível de satisfação com a forma através da qual a 
EADI vinha sendo utilizada pelas suas empresas. A maior parte dos respondentes se encontra satisfeita, porém, com algumas ressalvas, tal como pode ser observado nas declarações exemplificadas a seguir:

Como o nosso Centro de Treinamento está hoje, ele atende as nossas expectativas. Mas a minha vontade era já ter a nossa Universidade Corporativa estabelecida, com as nossas competências definidas, podendo assim ter resultados que a gestão estratégica da empresa percebesse de forma mais clara. [entrevistado]

Nós não temos tutores que acompanham os cursos e por isso ocorrem muitas desistências. Os cursos são abertos a todos os colaboradores, mas, por exemplo, o analista econômico pode fazer o curso "Delegando Responsabilidades", mas ele não tem nenhum subordinado. Isso ocorre porque há um ano tínhamos outros interesses, outros objetivos, mas hoje, não. Hoje amadurecemos e estamos mudando, pensando em mudar de ferramenta, mudar a visão, a forma de enxergar a EADI aqui dentro da empresa. [entrevistado]

Portanto, observa-se que, apesar de as empresas estarem satisfeitas com o seu desempenho atual, elas percebem que existem vários pontos a melhorar. E todas sabem que, devido ao pouco tempo de utilização da EADI como um recurso de capacitação para os colaboradores, ainda se tem muito a aprender. Como disse um dos entrevistados, a empresa acaba tendo de aprender, na prática, como administrar seus cursos de EADI: "é o ônus de se ser inovador e de aprender com os erros, com o que deu certo e com o que não deu".

\section{CONSIDERAÇÕES FINAIS}

Este estudo teve como objetivo identificar características das iniciativas de EADI na capacitação de seus colaboradores em grandes empresas privadas brasileiras. Alguns dos principais resultados encontrados são apresentados no Quadro 3. Ainda que as características identificadas não possam ser generalizadas, elas trazem subsídios para a ampliação de pesquisas futuras e para reflexões sobre o estágio atual do desenvolvimento da EADI nas empresas brasileiras.

Uma dessas reflexões está no estágio de maturidade das iniciativas. Percebe-se que ainda é baixa a compreensão da importância de alguns dos elementos que são freqüentemente enfatizados por educadores e por pesqui- sadores da área. Isso fica claro quando se verifica que as soluções para os problemas relacionados aos cursos de capacitação são basicamente selecionadas pelo "método da tentativa e erro", e quando é constatado que não existe uma percepção efetiva do valor da interação na criação do conhecimento. Isso continua sendo válido ao ser enfatizado que, mesmo com o potencial da comunicação virtual, a falta de contato social ainda é destacada como um fator limitante relevante. Portanto, a presente análise permite inferir que as possibilidades da EADI não são plenamente exploradas.

Um dos prováveis motivos para essa realidade está no foco de muitas das iniciativas implementadas e analisadas: a redução de custos. A Internet é vista mais como uma ferramenta para reduzir custos com o treinamento nas empresas do que como uma tecnologia que pode aprimorar e qualificar esses treinamentos, abrindo portas para diversas inovações. A inexistência, na maioria dos casos analisados, de um método efetivo de avaliação dos treinamentos realizados é um indicador desse contexto, principalmente quando a avaliação realizada é apenas restrita à análise dos custos envolvidos. Percebe-se que ainda é baixo o alinhamento entre as iniciativas de EADI e as estratégias de negócios das empresas.

Cabe destacar dois dos principais limites da presente pesquisa. O primeiro é o fato de se tratar de uma pesquisa de cunho exploratório, cujos resultados obtidos não podem ser generalizados para outras situações (YIN, 2001) que não as nela analisadas, mas que nem por isso deixam de ser válidos, uma vez que fornecem informações sobre como algumas empresas estão utilizando a EADI. O segundo é o fato de a pesquisa estar principalmente baseada no depoimento de pessoas que integram a administração dos programas de EADI nas empresas. Deve ser considerado que a percepção das pessoas a respeito do fenômeno em estudo sofre várias influências, impossíveis de ser controladas pelo pesquisador. E que, portanto, tais depoimentos apresentam determinados vieses metodológicos, ou seja, podem ser caracterizados como percepções tendenciosas da realidade analisada.

Como sugestões para pesquisas futuras, podem-se utilizar as informações ora identificadas para construir um instrumento quantitativo que permita traçar um perfil mais preciso das características das iniciativas de EADI nas empresas nacionais. Adicionalmente, sugerese pesquisar um método de avaliação mais adequado para a EADI nas empresas e alguma forma alternativa de mensurar o retorno do investimento em Educação a Distância, que não seja a simples comparação com o treinamento presencial. 


\section{ARTIGOS - EDUCAÇÃO A DISTÂNCIA VIA INTERNET EM GRANDES EMPRESAS BRASILEIRAS}

Quadro 3 - Principais resultados da pesquisa

TÓPICOS

Informações sobre os cursos de EADI.

Tecnologias utilizadas nos cursos de EADI.

Avaliação dos cursos de EADI.

Principais Vantagens, desvantagens e condições fundamentais para que a EADI produza resultados.

\section{PRINCIPAIS RESULTADOS}

- todas as empresas permitem acesso aos cursos de EADI no local de trabalho, sendo que seis delas também permitem acesso externo;

- os colaboradores são o principal público-alvo dos cursos de EADI, sendo que, em algumas das empresas, os cursos também estão sendo estendidos aos seus parceiros;

- para guiar a capacitação de seus colaboradores para os cursos de EADI, a gestão de pessoas por competências é utilizada em quatro empresas. Com o mesmo objetivo, outra das empresas estudadas utiliza a gestão por performance;

- três empresas estão monitorando os seus cursos de EADI;

- os cursos de EADI, na maior parte das empresas pesquisadas, são realizados de forma individual, sendo fortemente baseados na auto-instrução, sem interação entre os seus participantes;

- cursos de EADI, na sua maioria, objetivam melhorar as soft skills e também os conhecimentos relativos a aplicações para PCs;

- grande ênfase nos cursos táticos e operacionais, porém também foi constatado que são feitos investimentos nos cursos gerenciais;

- o português é o idioma predominante nos cursos de EADI, e o inglês é o idioma mais utilizado nas empresas estrangeiras.

- Intranet é a principal ferramenta para acesso aos cursos de EADI;

- três empresas não disponibilizam qualquer ferramenta de comunicação aos colaboradores;

- dez das empresas estudadas utilizam "cursos de prateleira" e, dentre estas, cinco contratam empresas especializadas para desenvolver cursos personalizados. Porém, cinco das empresas, todas de capital estrangeiro, desenvolvem internamente os seus cursos, mas isto não impede que quatro delas também comprem cursos prontos;

- as empresas que desenvolvem internamente seus cursos também desenvolvem seus conteúdos, o que não acontece nas demais;

- textos, figuras e fotografias são as formas mais utilizadas para a apresentação de conteúdos nos cursos.

- falta de um padrão comum de avaliação;

- o investimento inicial variou entre $\mathrm{R} \$ 70.000,00$ e $\mathrm{R} \$ 400.000,00$;

- para medir o ROI, foram identificadas três correntes: a) verificação do retorno através da comparação dos gastos do treinamento presencial com o virtual; b) verificação do retorno através dos resultados do negócio (verificado através dos objetivos de área); c) nenhuma verificação de retorno.

- vantagens: atinge um grande número de pessoas ao mesmo tempo, em diferentes locais; facilidade de aumentar o número de alunos por curso; redução do custo total com treinamento;

- desvantagens: altos custos iniciais dos programas; dificuldade de encontrar método de avaliação confiável; falta de socialização entre os participantes;

- condições fundamentais: necessidade de um líder, engajado neste processo, que ocupe uma posição hierárquica mais alta; adequação cultural e ambiental; plano de comunicação eficiente e eficaz sobre a capacitação através da EADI; uma ferramenta eficiente e eficaz. 


\section{TATIANA GHEDINE · MAURÍCIO GREGIANIN TESTA · HENRIQUE MELLO RODRIGUES DE FREITAS}

\section{REFERÊNCIAS}

ALAVI, M. Computer-mediated collaborative learning: an empirical evaluation. MIS Quarterly, v. 18, n. 2, p. 159-175, 1994.

ALAVI, M; LEIDNER, D. Research commentary: technology-mediate learning. Information Systems Research, v. 12, n. 1, p.1-10, 2001.

BELLONI, M. Educação a Distância. Campinas: Autores Associados, 2001

CAMPBELL, J. Evaluating ALN: what works, who's learning? ALN Magazine, v. 1, n. 2, 1997.

CHEONG, C. E-learning: a provider's prospective. Internet and Higher Education, v. 4, n. 3, p. 337-352, 2002

HALL, B. Web-based training cookbook. Nova York: Wiley Computer Publishing, 1997.

HÄMÄLÄINEN, M; WHINSTON, A; VISHIK, S. Electronic markets for learning: education brokerages on the Internet. Communications of the ACM, v. 39, n. 6, p.51-58, 1996.

HARUN, M. Integrating e-learning in the workplace. Internet and Higher Education, v. 4, n.3, p. 301-310, 2002.

HENRY, P. E-learning technology, content and services. Education \& Training, v. 43, n. 4, p. 249-255, 2001.

KIRKPATRICK, D. Evaluating training programs: the four levels. São Francisco/EUA: Berrett-Koehler Publishers, 1998

LEIDNER, D.; JARVENPPA, S. The use of information technology to enhance management school education: a theoretical view. MIS Quarterly, v. 19, n. 3, p. 265-291, 1995.

MAIA, M; MEIRELLES, F. A tecnologia da informação e os modelos pedagógicos utilizados na educação a distância. In: ENCONTRO NACIONAL DA ANPAD, 28, 2004, Curitiba. Anais... [S.1]: ANPAD, 2004.

MALHOTRA, N. Pesquisa de marketing. Porto Alegre: Bookman, 2001.

MOORE, M; KEARSLEY, G. Distance education: a systems view. Belmont: Wadsworth, 1996

NACHMIAS, C; NACHMIAS, D. Research methods in the social sciences. New York: St. Marin's Press, 1996.

PALLOFF, R; PRATT, K. Building learning communities in cyberspace. San Francisco: Jossey-Bass, 1999.
PICCOLI, G; AHMAD, R; IVES, B. Web-based virtual learning environments: a research framework and a preliminary assessment of effectiveness in basic IT skills training. MIS Quarterly, v. 25, n. 4, p.401-426, 2001.

ROSA, V; MOREIRA, D. Educação a distância, um estudo de caso. In: CONGRESSO DA ASSOCIAÇÃO BRASILEIRA DE EDUCAÇÃO A DISTÂNCIA, 8, 2002, São Paulo. Anais... [S.1]: ANPAD, 2002.

ROSENBERG, M. E-learning: estratégia para a transmissão do conhecimento na era digital. São Paulo: Makron Books, 2002.

RUAS, R. Gestão por competências: uma contribuição à estratégia das organizações. In: BOFF, L. H., ANTONELLO, C. S., RUAS, R. Aprendizagem Organizacional e Competências. Porto Alegre: Bookman, 2005.

SALOMON, G; ALMOG, T. Educational psychology and technology: a matter of reciprocal relations. Teacher College Record, v. 100, n. 1, p. 222-241, 1998

SALAS, E. e outros. Emerging themes in distance learning research and practice: some food for thought. International Journal of Management Review, v. 4, n. 2, p.135-153, 2002

STRAZZO, D; WENTLING, T. L. A study of e-learning practices in selected Fortune 100 companies. The NCSA e-learning group University of Illinois, 2000

TESTA, M. G; FREITAS, H. Web-based distance learning programmes: an exploratory investigation of its critical success factors. Revista Eletrônica de Administração, v. 9, n. 6, 2003.

URDAN, T; WEGGEN, C. Corporate e-learning: exploring a new frontier WRHambrecht+CO, Mar. 2000

WELLE-STRAND, A; THUNE, T. E-learning policies, practices and challenges in two Norwegian organizations. Evaluation and Program Planning, v. 26, n. 2 , p. $85-92,2003$

WENTLING, T. e outros. E-learning: a review of literature. UrbanaChampaign: University of Illinois, 2000

YIN, R. Estudo de caso. Porto Alegre: Bookman, 2001

YOUNG, K. The effective deployment of e-learning. Industrial and Commercial Training, v. 33, n. 1, p. 5-11, 2001

YOUNG, K. Is e-learning delivering ROI. Industrial and Commercial Training, v. 34 , n. 2, p. 54-62, 2002 